\title{
Arbor
}

\section{La Colección de Tapices de la Corona de España. Notas sobre su formación y conservación.}

\section{Concha Herrero Carretero}

Arbor CLXIX, 665 (Mayo 2001), 163-192 pp.

\section{Formación y conservación de la Colección de Tapices de la Corona de España}

La Colección de Tapices de la Corona de España puede considerarse una de las mayores del mundo, gracias al patrocinio de los Monarcas que enriquecieron el patrimonio de la Corona con sucesivas adquisiciones y a la custodia ejercida por el Real Oficio de la Tapicería. Medidas excepcionales que permitieron la pervivencia de una colección tan rica en calidad y en cantidad, paradigma de las colecciones europeas, fueron las disposiciones testamentarias de los Monarcas de la Casa de Austria cuya progresiva evolución, desde Carlos V a Carlos II, vinculó las tapicerías al servicio de los príncipes herederos y las imprimió un carácter de bien afecto representativo de la autoridad de la Corona.

Los tapices, en las disposiciones testamentarias de Isabel la Católica y sus antecesores, habían figurado como parte del caudal testamentario de los Monarcas. Así, la Reina dispuso en sus últimas voluntades que se pagasen todas las deudas hereditarias con sus bienes muebles, considerados reserva del erario público, motivo por el que la Colección de Tapices reunida por Isabel se desperdigó en la almoneda que, al año de su muerte, se celebró en Toro. Aunque Carlos V determinó, siguiendo el ejemplo de su abuela Isabel, que sus deudas fuesen pagadas con los bienes muebles, propuso que las alhajas, en especial la tapicería rica y demás parte preciosa del mobiliario de los Palacios, no saliesen 


\section{Concha Herrero Carretero}

del poder de su sucesor el Príncipe Don Felipe. Sólo a partir de las disposiciones testamentarias de Felipe II, estos bienes dejaron definitivamente de ser considerados como un conjunto de bienes de familia, expresándose de modo terminante, tanto en su testamento como en el codicilo, otorgado en San Lorenzo, el 23 de agosto de 1597, la prohibición de enajenar cosa alguna de las pertenecientes a la Corona, y la obligación de velar por la conservación del Patrimonio Real.

Felipe III y Felipe IV refrendaron estas disposiciones testamentarias, y Carlos II las amplió vinculando las tapicerías a los Palacios que adornaban, lo que fue de nuevo confirmado por Felipe V, primer Monarca de la Casa de Borbón, en su testamento, unido al acta de su renuncia y abdicación, fechados el 10 de enero de 1724. A la muerte de Carlos II, último Monarca de la Casa de Habsburgo en España, la Colección Real de Tapices contaba con un singular número de obras maestras procedentes de los telares dirigidos por los más renombrados maestros flamencos. El Alcázar de Madrid, residencia principal y habitual del Monarca, mereció en su testamentaría, elaborada entre 1700 y 1709 , un inventario por materias y dependencias entre las que se encontraba el Oficio de Tapicería. La redacción del inventario de las alhajas de la Real Tapicería corrió a cargo del Tapicero Mayor, Felipe de Torres y Salazar. La Colección de Tapices, asentada en ciento nueve partidas, la heredó íntegra Felipe V, siendo buena prueba de la ejemplar custodia ejercida por el Oficio de Tapicería para su conservación y enriquecimiento ${ }^{1}$.

\section{La custodia de la colección: El Real oficio de tapicería}

Los jefes del Real Oficio de Tapicería, con sus mozos y oficiales, eran los encargados de la custodia de tapices y colgaduras de verano e invierno, además de las alfombras, tapetes, almohadas, camas, doseles y sitiales que, en los cuartos destinados al oficio, se conservaban doblados en cofres y cajas, bien cerrados y seguros para evitar robos y deterioros. El oficio se encargaba del cuelgue y descuelgue de los paños en los aposentos reales según las estaciones, del traslado de las tapicerías en las jornadas a los Reales Sitios, de armar los doseles, y de colgar las fachadas de Palacio en funciones señaladas como entradas y juramentos reales, o en procesiones como la del Corpus.

Las etiquetas generales, aprobadas en 1647 por Felipe IV, enumeraban como tareas correspondientes al Jefe del Oficio de Tapicería, las de redactar los inventarios de las alhajas a él encomendadas, re- 
La Colección de Tapices de la Corona de España...

conocer la historia representada en los tapices, expresar los materiales con que estaban tejidos, valorar la calidad y textura del tejido, recontar el número de paños que conformaban cada una de las tapicerías, medir la corrida y la caída de los paños, tasarlos económicamente, y dar las indicaciones pertinentes sobre sus diferentes emplazamientos en Palacios y Sitios Reales. Pero, ante todo, debían tener particular cuidado para que estuvieran bien tratados y limpios, y presenciar cómo los ayudas, sotoayudas y mozos del Oficio los desdoblaban, sacudían y limpiaban.

La recompostura de las tapicerías, es decir, el arreglo y mantenimiemto de las piezas, los procesos de costura, aderezo y forrado para mantener en uso los paños, fue tarea encomendada en el Oficio a los maestros retupidores. Requisito indispensable para ocupar el empleo de ayuda del Oficio de Tapicería, era el ejercicio de retupidor, lo que demuestra cuál era el fin esencial del mismo. La plaza de retupidor, establecida en la Real Casa desde el 11 de julio de 1560, debía recaer en personas de habilidad, aplicación y graduación en el arte de la tapicería. El primero que entró a servirla fue Cornelio Juanes, natural de Bruselas, como aderezador de la tapicería del Rey Felipe II. La plaza tuvo gran importancia desde 1673, año en que la Reina Mariana de Austria (1634-1696), segunda esposa de Felipe IV y madre de Carlos II, nombró maestro retupidor a Enrique Jestelein, al que sucedió su hijo Bernardo Jestelein hasta 1699, año de su muerte. Carlos II hizo venir de Flandes a Esteban Vandenberch, por ser uno de los mejores maestros en aquellos países, llegando a Madrid en noviembre de 1700. Felipe V mantuvo en la plaza a su hijo, Francisco Vandenberch, aunque a partir de 1750 encomendó las importantes labores de recomposición y aderezo de las tapicerías de la Colección Real a los hermanos Vandergoten, maestros de la Real Fábrica de Tapices establecida en Madrid ${ }^{2}$.

\section{Tesoro de devoción de Isabel la Católica y Juana la Loca}

Los dos paños más antiguos conservados en la Colección de Tapices de la Corona de España, el Nacimiento de Jesús, paño en forma de retablo con escenas basadas en los relatos proféticos de Miqueas e Isaías, y la Misa de San Gregorio, paño de devoción eucarística inspirado en la Leyenda Dorada, formaban parte de la espléndida colección reunida por Isabel la Católica y desperdigada, sin embargo, al ser puesta en almoneda en la ciudad de Toro, a principios de 1505. 
El Nacimiento de Jesús fue recibido por Sancho de Paredes, camarero de la Reina, en la villa de Alcalá de Henares, el 2 de abril de 1492, de manos de Hernán Núñez Coronel, y fue asentado en el libro de cuentas de dicho camarero como un paño grande de ras con oro, que está en lo alto del, Dios Padre, çercado de serafines y ángeles, y debajo el nasçimiento e Josepe con una candela en la mano, que tiene de cayda quatro varas e una terçia, de largo quatro varas ${ }^{3}$. $\mathrm{Al}$ no figurar entre los 128 relacionados por el contador Juan Velázquez en la almoneda de Toro, de 1505, se libró de pasar a manos particulares y en definitiva de su desaparición.

Dos paños de la Misa de San Gregorio, probablemente tejidos por el mismo cartón, figuraron asentados entre los bienes de la Reina. Uno adquirido al tapicero y comerciante flamenco, Matís de Guirla, en Medina del Campo, por el que se pagaron, en 1494, cincuenta y seis mil dosicentos cincuenta maravedises, y que más tarde Isabel enviaría a su hija doña María de Portugal, y un segundo paño de la Misa de San Gregorio que le regaló su hija doña Juana, y que Fernando el Católico, a la muerte de Isabel, ordenó le fuera devuelto. La más completa descripción iconográfica de este último paño, tejido en la manufactura bruselense de Pierre van Aelst y conservado en la Colección Real, nos la ofrece la combinación de las descripciones correspondientes a ambos paños redactadas, una por Sancho de Paredes, camarero de la Reina, y otra por el contador Juan Velázquez. La escena principal del paño adquirido a Matís de Guirla —en lo alto nuestro Señor con las plagas y la escalera y la lança con todos los misterios de la Pasión, e debaxo del, San Gregorio vestido diziendo Misa, e a la parte derecha, detrás del, un diácono con un alva verde que alça la casulla de San Gregorio en la mano, e de la otra parte, a la mano yzquierda, un cardenal con otro diacono, con una cruz en la mano, e detrás del un obispo e dos pajes ${ }^{4}$ - tapiz regalado, más tarde, por Isabel a su hija, María de Portugal, es la misma escena tejida en el paño regalado por Juana.

La descripción minuciosa de las escenas secundarias y la transcripción de las leyendas latinas de la Misa de San Gregorio, regalada por Juana de Castilla a su madre, Isabel la Católica, redactadas por Juan Velázquez, enumeran los pasajes de la Pasión de Cristo que enmarcan la escena central - tiene a la parte derecha en lo más alto, un crucifixo con Nuestro Señor puesto en la Cruz, e Nuestra Señora e San Juan a los lados, e debaxo cómo lleva Nuestro Señor la cruz a cuestas, y en la parte esquierda, en lo alto, cómo está Nuestro Señor orando en el huerto, e debaxo cómo le prendieron, San Pedro con la 
oreja del judío en la mano por ponergela, y en lo baxo, a la parte esquierda, David profeta con un rótulo en la mano que dize "Panem Angelorum manducavit omo», y en la parte derecha, Sant Agustín con un rótulo que dize "Sacramentum ex posibilis gracia visibilis forma» ${ }^{5}$.

Sólo tres paños más de la colección de Isabel, han podido ser identificados en colecciones extranjeras al encontrar claras correspondencias iconográficas con los asientos de los inventarios de la Reina, transcritos por Sánchez Cantón. Los paños titulados Redención de la humanidad por la encarnación y muerte de Cristo y el Triunfo de la Fama, se conservan en el Metropolitan Museum of Art, de Nueva York ${ }^{6}$, y el titulado Maximiliano y María de Borgoña jugando al ajedrez ${ }^{7}$, asentado desde 1503 en el tesoro del Alcázar de Segovia como un paño de unas figuras grandes francesas, unos encasamentos e tiene en medio dos figuras de un ombre e una muger que juegan al axedrez, vendido a la marquesa de Moya en la almoneda de Toro, en $1505^{8}$, se conserva actualmente en la Stiftung Abegg, de Riggisber (Berna).

Las adquisiciones de Juana de Castilla, hija de Isabel, enriquecieron la Colección Real con la incorporación de importantes tapices del período renacentista flamenco. La manufactura de Pieter van Edinghen o Pierre van Aelst fue una de las más afamadas de Bruselas. Nacido hacia 1450 , cerca de la ciudad de Alost, fue nombrado en 1502 «valet de chambre et tapissier» de Felipe el Hermoso, a quien en ese mismo año, acompañó en su viaje a España. Este tapicero tejió numerosos paños de devoción para la Reina Juana, todos ellos con escenas entresacadas de las Sagradas Escrituras, relacionadas con la salvación y redención del mundo por el sacrificio del Hijo de Dios. El carácter alegórico-bíblico de los paños respondía a una finalidad eucarística y apologética, y reflejaba el contenido de los textos contemporáneos de padres y predicadores de la Iglesia. Así los seis paños de la Devoción de Nuestra Señora (1500-1509) o Paños de Oro, que la Reina adquirió en 1502 y conservó en su interminable reclusión en Tordesillas, desde 1509 hasta su muerte en $1555^{9}$.

\section{Herencias de Margarita de Austria y de María de Hungría}

Margarita de Austria (1480-1530), hermana de Felipe el Hermoso y gobernadora de los Países Bajos, contribuyó a engrandecer la colección al disponer que algunos de los tapices que habían decorado su palacio en Malinas fueran entregados a su sobrino predilecto. Por las dispo- 
siciones de su testamento, Carlos se convirtió en heredero de tapicerías de gran calidad y significación iconográfica, como la Pasión de Cristo, o el llamado Dosel de Carlos V, tejidos en Bruselas, entre 1518 y 1524, por Pieter Pannemaker, fundador de una de las dinastías de tapiceros más representativa de la producción bruselense ${ }^{10}$.

Bajo el gobierno de María de Hungría (1505-1558), hija de Felipe el Hermoso y de Juana de Castilla, Flandes atravesó uno de sus momentos de mayor esplendor artístico, debido al mecenazgo y protección de artistas ejercido, no sólo por la Gobernadora, sino también por las ciudades, corporaciones, altos dignatarios y miembros de la Corte. Las ricas tapicerías que adornaron el palacio de María de Hungría en Bins o Binche, de extremada fineza, hechas de seda, oro y plata, con maravillosas figuras, como las describió Calvete de Estrella, eran fiel reflejo del mundo flamenco, mezcla de costumbres tradicionales y de la cultura clasicista y manierista irradiada desde Italia. A María de Hungría debemos que la Colección Real de España cuente con importantes series heredadas por Felipe II, al disponer en su testamento que fueran entregadas a su sobrino. Entre ellas figuraba la misma tapicería de los Siete Pecados Mortales que había decorado la cámara real preparada para recibir al Príncipe y al Emperador, en el palacio de Binche. Los siete paños, fruto de la colaboración artística del pintor Pierre Coeck van Aelst y del tejedor Wilhelm Pannemaker, fueron heredados por Felipe II según indicación marginal del inventario redactado por Rogier Patie, tesorero de la Reina. Otras tapicerías ricas, heredadas por Felipe II de su amada tía, fueron la Historia de Hércules, la Historia de Dido y Eneas, la Historia de Escipión, la Historia de Venus, dos tapicerías de Moisés, la Historia de Tobías y la Historia de San Pablo, todas ellas conservada en la Colección Real ${ }^{11}$.

\section{Adquisiciones de Carlos V y Felipe II}

Al Reinado de Carlos V y a su gusto por las tapicerías, se debe la adquisición de grandes series tejidas en los telares bruselenses de Pierre van Aelst o de la familia Pannemaker. Pierre van Aelst, a partir de 1510, gozó del cargo de Ayuda de Cámara y Tapicero de la Corte de Carlos de Habsburgo, para el que tejió la tapicería conocida como Los Honores o La Fortuna que conmemoraba su coronación como Emperador en Aix-la-Chapelle, el 23 de octubre de 1520. La iconografía de los nueve paños que ilustraba las virtudes y vicios que el soberano debía practicar o evitar, respondía a la establecida para celebrar las 
La Colección de Tapices de la Corona de España...

suntuosas entradas de reyes y príncipes en las ciudades de los Países Bajos ${ }^{12}$

La Conquista de Túnez, otra de las grandes series encargadas por Carlos V, realizada entre 1548 y 1554 por Wilhelm Pannemaker, fue la crónica tejida que ilustró la campaña del Emperador contra Solimán, príncipe de los turcos, según composiciones de Jan Cornelisz Vermeyen. Este pintor fue llamado en 1534 por el Emperador para asistir, como pintor e ingeniero, de la toma de Túnez, durante la que ejecutó los croquis que, más adelante, le sirvieron de modelo para los cartones de la tapicería ${ }^{13}$.

En 1548, Carlos V mandó llamar a su hijo Felipe para hacerlo jurar por heredero y sucesor en los Estados de Flandes. Juan Calvete de Estrella, como criado del Príncipe, le acompañó en su viaje a Flandes, y con él asistió a las fantásticas y sorprendentes fiestas con que la gobernadora María de Hungría obsequió a su hermano el Emperador, y al Príncipe, su sobrino. Principal objeto de admiración y de descripción en su viaje, fueron las tapicerías y los arcos de triunfo, ornato de las ciudades que jalonaban el itinerario y señalaban la importancia de Bruselas y de su floreciente industria tapicera.

Al reinado de Felipe II (1555-1598) correspondió la adquisición de ricos tapices tejidos en los telares del maestro Wilhelm Pannemaker, el hijo más sobresaliente de Pieter Pannemaker, tapicero de la corte de Margarita de Austria, al que sucedió en la dirección como maestro de la manufactura bruselense donde se tejieron las tapicerías más grandiosas del momento. La espectacular serie del Apocalipsis, basada en cartones atribuidos a Bernard van Orley, inspirado en las estampas de Alberto Durero, fue rehecha por Wilhelm Pannemaker, junto con la Historia de Noé, al desaparecer ambas tapicerías en el naufragio de la escuadra que conducía al Rey a Laredo, el 8 de septiembre de 1559. Finalizada la labor, Pannemaker se encargó personalmente de transportar a Madrid los paños por él tejidos, más los salvados del desastre de 1559, con los monogramas del maestro Guillaume Dermoyen y llamados desde aquel entonces Los ahogados. El viaje comenzó en el verano de 1561 y finalizó en Madrid, el 22 de octubre de 1562.

Jan Vermeyen, el pintor de la Conquista de Túnez, también entregaría a la manufactura de Wilhelm Pannemaker los cartones de la tapicería de asunto mitológico, los amores de Vertumno y Pomona, asunto mitológico inspirado en el poema de Ovidio, "Las Metamorfosis». Los paños que relatan las sucesivas transformaciones del dios Vertumno hasta vencer la indiferencia amorosa de la diosa de los frutos, ya 
sorprendieron gratamente a Felipe II, en 1549, cuando contempló la tapicería que ornaba el cuarto real dispuesto por María de Hungría como alojamiento del Emperador y del Príncipe en su palacio de Binche. Felipe II mandó tejer una serie por los mismos cartones a su tapicero Pannemaker, para decorar con ella los muros del Alcázar de Madrid.

Por primera vez, en los inventarios de tapices de Felipe II, se asentaron, entre sus alhajas, nueve paños de seda y lana, de la Historia de los Apóstoles -tejidos por Johann van Thiegen y Nikolaus Leyniers, según los cartones encargados por León $\mathrm{X}$ a Rafael y a su discípulo G. F. Penni, il Fattore- y una Historia de Ciro, de diez paños, tejidos con hilo de oro y plata por los mismos maestros bruselenses, sobre cartones atribuidos a Marten van Heemskerk, inspirados en los «Nueve libros de la Historia» de Herodoto de Halicarnaso ${ }^{14}$.

\section{Tapices de los Archiduques Alberto de Austria e Isabel Clara Eugenia}

En el siglo XVII, Bruselas asistió a un nuevo renacimiento del arte del tapiz, bajo la protección de la Infanta Isabel Clara Eugenia (1566-1633), hija de Felipe II e Isabel de Valois. A su gobierno en los Países Bajos, desde 1599 a 1633, correspondió el gran florecimiento artístico unido al nombre de Pieter Paul Rubens quien introdujo una concepción barroca que unía naturalismo, suntuosidad y reminiscencias clásicas, y cuyos cartones, realizados al óleo, supusieron una complicación considerable, al enfrentar a los tapiceros con modelos que, concebidos pictóricamente, no tenían en cuenta los numerosos detalles de orden técnico a los que los antiguos cartonistas les tenían acostumbrados.

La Apoteosis de la Eucaristía o Los Triunfos de la nueva Ley de la Iglesia y el Sacro Evangelio, abatido el Gentilismo y todos los Ritos Antiguos, excepcional serie de tapices del siglo XVII, fue encargada en 1625, por Isabel Clara Eugenia para el Convento de Descalzas Reales, de Madrid ${ }^{15}$. Los cartones realizados por Rubens durante su estancia en Bruselas, entre 1625 y 1626, se encontraban en el convento de dominicas recoletas de la Purísima Concepción en la villa de Loeches, en 1742, como describe Antonio Palomino y Velasco en su Vida de pintores y estatuarios eminentes españoles. Hoy se encuentran repartidos entre el Museo del Louvre y el Ringling Museum of Art de Sarasota. Los tapices fueron tejidos en la manufactura de Jan Raes en colaboración 
con los talleres dirigidos por Jakob Geubels, Jacques Fobert y Jan Vervoert, como demuestran los monogramas que aparecen tejidos en los orillos de los paños. Isabel autorizó, el 14 de julio de 1628, la salida de dos carromatos cargados con la tapicería en dirección a España ${ }^{16}$.

El 1 de diciembre de 1633, Isabel moría en Bruselas, y nueve meses más tarde, Felipe IV dio la orden de que se eligieran sus mejores tapices con destino al Alcázar de Madrid. Entre ellos se encontraban siete paños de las Batallas del Archiduque Alberto, tapicería regalada por el magistrado de la ciudad de Amberes al Archiduque Alberto (1559-1621), con motivo de su feliz entrada en la ciudad, en diciembre de 1599. La realización de los bocetos y cartones había sido encomendada a Octavio van Veen y a Jan Snellinck el Viejo, pintores de la corte de los Archiduques, y el tejido de la tapicería a la manufactura del maestro Martín Reynbouts, durante los últimos cuatro años del siglo XVI. Los siete paños aparecerán asentados por primera vez en el inventario de las Tapicerías de Felipe IV, de 1666, como las Batallas $y$ Sitios de los triunfos del Archiduque Alberto ${ }^{17}$.

\section{Series adquiridas por Felipe IV para el Palacio del Buen Retiro}

El reinado de Felipe IV (1621-1665) se caracterizó por haberse llevado a cabo una de las empresas de coleccionismo a gran escala mejor organizadas y puestas en práctica de todo el siglo XVII. Entre 1633 y 1640, diferentes tapices fueron adquiridos, encargados o confiscados por el Rey y su valido, el Conde Duque de Olivares, para la decoración del Palacio del Buen Retiro. Entre las series adquiridas para tal fin se encuentran algunas de las más famosas tapicerías tejidas en la manufactura bruselense de Jan Raes, basadas en composiciones del pintor Antoine Sallaert, como la Historia de Teseo; la tapicería alegórica de vicios y virtudes, conocida en los inventarios del Oficio de Tapicería de Palacio como Historia de la Vida del Hombre ${ }^{18}$, o la serie metamórfica de la Historia de Faetón, tejida en la Arazzeria Medicea, según cartones del pintor de la escuela florentina Alessandro Allori ${ }^{19}$.

Las relaciones comerciales entre España y los Países Bajos fueron declinando a lo largo de la segunda mitad del siglo XVII, hasta que a comienzos del siglo XVIII, las relaciones con los grandes talleres flamencos quedaron bloqueadas como consecuencia de la Paz de Utrecht 
que desvinculó los Países Bajos de la Corona de España y dio por finalizada la Guerra de Sucesión.

\section{El mecenazgo de la Casa de Borbón: El gusto por la tapicería antigua}

Felipe V, nieto de Luis XIV, inició en España la dinastía borbónica tras la muerte de Carlos II, el último Habsburgo español. Aconsejado por su primer ministro, Giulio Alberoni, decidió, en 1719, establecer una manufactura de tapices en Madrid, y suplir con ella el tejido de tapices efectuado hasta entonces por los talleres flamencos que habían atendido los encargos reales de la Casa de Austria. La Colección de Tapices reunida por la Casa de Habsburgo, heredada por Felipe V, quedó consignada en el inventario redactado en 1747, tras la muerte del Monarca, como testimonio del vínculo entre aquella y la incipiente colección de los Borbones. Además de las tapicerías antiguas que figuraron en los documentos sucesorios de Carlos II, quedaron asentadas nuevas adquisiciones flamencas, las tapicerías confiscadas tras la Guerra de Sucesión, y las llamadas tapicerías nuevas realizadas en las manufacturas de la Casa de Santa Bárbara y de la Casa de Santa Isabel, de Madrid, establecidas en la Corte desde 1720. La predilección por las tapicerías flamencas o tapicerías antiguas se reflejó tanto en la decoración del Buen Retiro, residencia de los Monarcas de Borbón durante los treinta años que transcurrieron hasta la finalización del Nuevo Real Palacio, como en la compra de series flamencas de los siglos XVI y XVII, durante los reinados de Felipe V y su sucesor Fernando VI.

En la testamentaría de Felipe V figuran, por primera vez, la Historia de Petrarca, ocho tapices que habían pertenecido al Duque de Abrantes, y la Historia del Cónsul Decio Mus, doce paños tejidos hacia 1625 en la manufactura bruselenses de Jan Raes y Jakob Geubels, según cartones de Pieter Paul Rubens, que fueron entregados al Oficio de la Tapicería por Bernardo de Loeches.

Isabel de Farnesio, segunda esposa de Felipe de Borbón, durante su estancia en Sevilla entre 1730 y 1734, compró una tapicería de ocho paños de la Historia de Escipión y Aníbal, tapicería que aparecerá asentada en la testamentaría de su hijo Carlos III, con cenefas de vicios y virtudes, tejida con hilo de oro en la manufactura de Henry Mattens a fines del siglo XVI y comienzos del siglo XVII, sobre los 
mismos cartones de Giulio Romano utilizados para tejer la serie de María de Hungría, heredada Felipe II.

Más importantes aún fueron las compras de tapices flamencos efectuadas, entre 1752 y 1753, durante el reinado de Fernando VI. Por real orden de 18 de febrero de 1752, Nicolás Manzano, jefe del Oficio de Tapicería, adquirió la serie mitológica de veintiocho paños de la Fábulas de Venus y Adonis, Diana y Apolo, procedente de los bienes testamentarios de José de la Quintana. Los paños inspirados en los hexámetros del libro décimo de las Metamorfosis de Ovidio, fueron tejidos en la segunda mitad del siglo XVII según cartones de Jan Boeckhorst, discípulo de Jakob Jordaens, en la manufactura bruselense de Guillem van Leefdael.

Otra importante adquisición por consejo y proposición del Marqués de Villafranca fue la compra, para la casa de Su Majestad, de la Historia de la Gran Cenobia, reina de Palmira. Nicolás de Francia, tesorero mayor, pagó cincuenta y un mil reales a Mateo Barquero por doce tapices, cuatro sobreventanas, cuatro sobrepuertas y cuatro entrepuertas de seda fina y muy buenos colores. Se trata de la tapicería tejida por Geerard Peemans sobre cartones de Justus van Egmont (1601-1674), inspirados en la obra de Jean Tristan de Saint Amant, «Commentaires historiques contenant l'histoire générale des Empereurs, Cesares et Tyrans de l'Empire Romain»(1644).

Tres tapicerías más fueron adquiridas un año después, en 1753, la Historia de Dido y Eneas, con cenefas de flores, angelotes y pavos reales; la Historia de Ciro, seis paños tejidos en Amberes, en el siglo XVI, sobre cartones atribuidos a Michiel Coxcie (1499-1592) y que fue denominada en los inventarios del Oficio de Tapicería como Ciro chico para diferenciarla de la Historia de Ciro, de Felipe II; por último, la Historia de Marco Antonio y Cleopatra, con cenefas de columnas salomónicas y guirnaldas de frutos con corona dorada en lo alto, tapicería tejida según cartones de Karel van Mander (1579-1623) ${ }^{20}$.

\section{Las tapicerías nuevas y la decoración de los Reales Sitios en el siglo XVIII}

El establecimiento de la manufactura de tapices madrileña durante el reinado de Felipe $\mathrm{V}$ acrecentó la colección de la Corona de España con el tejido de grandes series de tapicería -Cacerías con escudos, Escenas flamencas, Historia de don Quijote, Historia de Telémaco, Conquista de Túnez e Historia de Ciro- con un claro programa iconográfico, 
continuación de las directrices flamencas vigentes durante los siglos XVI y XVII. Estas tapicerías mantuvieron el carácter de series mitológicas, históricas o heroicas, propio de la producción flamenca a lo largo de los siglos XVI y XVII. Las réplicas de la Conquista de Túnez o de la Historia de Ciro demostraron el valor asignado a las tapicerías originales de Carlos V y Felipe II, que fueron preservadas así del uso continuado a que eran sometidas.

Un ampuloso y erudito programa decorativo ideado por el Padre benedictino fray Martín Sarmiento para realizar la «Tapicería de las más famosas Acciones del Rey Padre», con la que Felipe V y Fernando VI idearon vestir las principales piezas del primer proyecto del Palacio Nuevo, fue desechado por Carlos III. El inventario redactado tras el fallecimiento del Rey, el 14 de diciembre de 1788, prueba que sólo cuatro de las principales piezas que integraban el Cuarto del Rey fueron vestidas con tapices: la "pieza de vestir», con la tapicería Estaciones del año, tejida durante el reinado de Fernando VI sobre cartones de Santiago Amiconi; la «pieza de cenar», con la tapicería de la Historia de José ${ }^{21}$; la «pieza donde comía S. M. difunto», con la tapicería de la Historia de David, Salomón y Absalón, ambas por cartones de Corrado Giaquinto y José del Castillo; y, por último, la «pieza dormitorio de S.M. difunto», con la Colgadura de adornos, flores y frutas, cuyos ejemplares fueron iniciados por Guillermo Anglois y continuados por José del Castillo quien, desde 1765 y bajo la dirección de Antonio Rafael Mengs, primer pintor de Cámara de Carlos III, entró al servicio real, y, por tanto, al servicio de la Real Fábrica de Tapices ${ }^{22}$.

Aunque el reinado de Carlos III mantuvo la tradicional copia de originales de David Teniers como modelo de los tapices que habían. de tejerse en la Fábrica para vestir los cuartos reales, la dirección artística de Antonio Rafael Mengs supuso la ruptura de la hegemonía flamenca en la composición de ejemplares para tapices. Bajo su inmediata dirección, José del Castillo realizó, entre 1776 y 1777, los cartones al estilo de las pinturas de Herculano, por cuyo modelo se tejieron los tapices del Gabinete de la Princesa de Asturias, en los Palacios de El Pardo y de San Lorenzo. El acontecimiento cultural más importante de todo el reinado de Carlos III, las excavaciones iniciadas en 1738 en las tres ciudades destruidas por la erupción del Vesubio del año 79 - Herculano, Pompeya y Stabies- quedó de esta manera reflejado en las tapicerías tejidas en la Fábrica de Madrid, bajo la dirección artística de Mengs.

Sin embargo, el principal cambio de modelos compositivos se produjo a partir de 1770 con la recepción de los trabajos realizados bajo la 
dirección de los pintores de cámara, Francisco Bayeu y Mariano Salvador Maella, y con el nombramiento de Ramón Bayeu y Francisco de Goya como pintores del Real Servicio, destinados a surtir de pinturas para imitar en los tapices que debían tejerse en la Fábrica ${ }^{23}$. Los tapices dejaron de ser colgaduras para convertirse en decoraciones murales fijas, enmarcadas en las piezas de los cuartos reales por frisos y molduras de madera. Los asuntos jocosos y agradables, obras de invención, que según las reglas del decoro debían ornar los Palacios de recreo de El Pardo y El Escorial, tuvieron su más claro exponente en los ejemplares entregados, a partir de 1775, por Francisco de Goya. Su trabajo como cartonista dio carácter propio a la producción de la Real Fábrica de Tapices de Madrid diferenciándola de la producción dieciochesca del resto de las manufacturas europeas.

Escenas campestres de descanso y bienestar rural, relacionadas con la periferia de la capital, y escenas lúdicas de juegos y pasatiempos típicos de la vida de esta zona, fueron destinadas por Francisco de Goya a seis habitaciones del Palacio de El Pardo - Comedor de los Príncipes (1776-1778), Dormitorio (1778-1779), Antedormitorio o Pieza de Cámara (1780), Dormitorio del infante don Fernando (1785), Comedor del Rey o Pieza de Conversación (1787) y Dormitorio de las Infantas (1788) - en las que se alude indirectamente al carácter suburbano de dicho Palacio.

Los últimos ejemplares realizados por Goya, en 1791, para la tapicería del Despacho de Carlos IV en San Lorenzo de El Escorial, le fueron exigidos tras las quejas presentadas por Livinio Stuyck al tener paradas las obras en la Fábrica por la falta de diseños y dibujos para tapices que estaba obligado a entregar, entre otros, Francisco de Goya. Su salud debilitada, su falta de interés por los adornos - dibujos de hojas, tallos y flores- y el diseño de alfombras que se le exigían, además de sus otras obligaciones no sólo como Pintor del Rey sino como primer Pintor de Cámara, le alejaron definitivamente de la labor de cartonista ${ }^{24}$.

La célebre Colección de Tapices reunida por los Monarcas de España a lo largo de tres siglos conserva más de quinientos paños flamencos de los siglos XVI y XVII, y más de ochocientos tapices españoles, tejidos durante el siglo XVIII en la Real Fábrica de Tapices de Madrid. La elaboración del primer inventario o registro histórico, fue encomendada por Alfonso XII al Conde Viudo de Valencia de Don Juan, disponiendo el Monarca que la casa Laurent fotografiara los paños seleccionados. Resultado de ambas tareas fue la publicación, en 1903, del primer catálogo ilustrado con excelentes reproducciones en blanco y negro de 
135 piezas señaladas de la producción flamenca ${ }^{25}$. Una segunda publicación, encomendada por Alfonso XIII a los profesores Elías Tormo y F. J. Sánchez Cantón, vio la luz en 1919. En ella se incorporó un aparato crítico y bibliográfico del que carecía el album fotográfico de 1903, y se recogieron noticias sobre un mayor número de tapicerías, haciendo especial hincapié en el necesario estudio de la producción española del siglo XVIII ${ }^{26}$. Los trabajos de investigación sobre la Colección Real de Tapices se han sucedido a lo largo del siglo XX, permitiendo la publicación, en 1986, de dos catálogos sobre la colección flamenca de los siglos XVI y XVII, y el inicio de un amplio proyecto de catalogación de la tapicería de producción española. La reciente edición del catálogo de los tapices tejidos en la Real Fábrica de Madrid, bajo el reinado de Felipe V, forma parte de este proyecto ${ }^{27}$.

La pervivencia de los paños de devoción adquiridos por Isabel la Católica y Juana de Castilla, las sucesivas herencias de las colecciones de Margarita de Austria y María de Hungría, las adquisiciones de los Monarcas de las Casas de Habsburgo y Borbón, así como el cuidado ejercido por el Oficio de Tapicería de Palacio y por los maestros de la Real Fábrica de Tapices de Madrid, permiten considerar la Colección de Tapices de la Corona de España como un tesoro textil único en el mundo. Sus paños y colgaduras reflejan, no sólo la historia de las mejores manufacturas flamencas, sino también, la evolución del estilo de los cartones para tapices, desde las creaciones de los primitivos flamencos hasta las novedosas composiciones barrocas del círculo de Rubens y las invenciones de Goya para la Real Fábrica de Tapices, donde el artista mostró el talento e ingenio que le hicieron sobresalir por encima de sus contemporáneos.

A través de la Colección se puede seguir, no sólo, el desarrollo de programas iconográficos de exaltación de la Monarquía, reflejo de las ideas y corrientes literarias del momento, sino también, el cambio de gusto y de planteamientos decorativos introducidos, a lo largo de cinco siglos, en los cuartos de Palacios y Residencias Reales de la Monarquía Española.

\section{Notas}

1 Sobre disposiciones testamentarias, ver Herrero, C. (1994) 288-289.

2 Sobre la organización del Real Oficio de Tapicería, ver Herrero, C. (1994) 298-305.

3 Carta de la Reina Católica mandando pagar a favor de Matís de Guirla el precio de unos tapices, en Revista de Archivos, Bibliotecas y Museos, 4 (1874) 459, y Libro de cuentas de Sancho de Paredes, ver Sánchez Cantón, F. J. (1950) 129. 


\section{La Colección de Tapices de la Corona de España...}

4 Libro de cuentas de Sancho de Paredes, ver Sánchez Cantón, F. J. (1950) 117-118.

5 Cédula del Rey Católico, ver Sánchez Cantón. F. J. (1950) 149-150.

6 Steppe, J. K. (1976) 204-205 y Delmarcel, G. (1999b) 70-71

7 Sobre la primera aparición en el mercado, ver "Notable works of art now on the market». The Burlington Magazine for Connoisseurs, diciembre 1927, lám. 29, y Sánchez Cantón, F. J. (1950) 100, lám. V.

8 Relaciones de la recámara de la Reina Católica a cargo de Juan Velázquez, ver Sánchez Cantón, F. J. (1950) 149.

9 Ferrandis, J. (1943) 344-345, y Herrero, C. (1986) 100-101.

10 Delmarcel, G (1992) 127-160.

11 Herrero, C. (1994) 291-292.

12 Delmarcel, G. (1999c).

13 Der Kriegszug Kaiser Karls V. gegen Tunis. Kartons und Tapisserien. (2000).

Viena. Kunsthistorisches Museum Wien, Viena, 2000.

14 Sobre los inventarios y colección de tapices reunida por Felipe II, ver Delmarcel, G (1999a) 153-178 y Buchanan, I. (1999) 131-152.

15 Sobre la llegada de las piezas y su destino en el monasterio, ver García, A (1999) 108-117.

16 Herrero, C (1999c) 176.

17 Nuevas aportaciones al volumen II del catálogo de Patrimonio Nacional, en Herrero, C. (1998) 83.

18 Herrero, C. (1999a) 105.

19 Nuevas aportaciones al volumen II del catálogo de Patrimonio Nacional, en Herrero, C. (1999b) 238-239.

20 Documentación sobre las compras efectuadas por Felipe V, Isabel de Farnesio y Fernando VI, en Herrero, C. (1999a) 109-110.

21 Herrero, C. (2001).

22 Herrero, C. (1993) 287.

23 Herrero, C. (1996a) 69-85.

24 Herrero, C. (1996b).

25 Valencia de Don Juan (1903) 2 volúmenes.

26 Tormo, E. y Sánchez Cantón, F. J. (1919).

27 Herrero, C. (2000).

\section{Bibliografía}

Buchanan, I. (1999): «The Tapestry Collection of King Philip II. New Documentation on Tapestries acquired during his visits to the Netherlands (1549-50 and 1555-59)». Gazette des Beaux-Arts 134, 131-152.

Delmarcel, G. (1992): «De Passietapijten van Margareta van Oostenrijk (ca. 1518-1524)». Nieuwe Gegevens en Documenten. Revue Belge d'Archéologie et d'Histoire de l'Art 61, 127-160.

Delmarcel, G. (1999a), «Le roi Philippe II d'Espagne et la Tapisserie. L'inventaire de Madrid de 1598", Gazette des Beaux-Arts 134, 153-178.

Delmarcel, G. (1999b): La Tapisserie flamande du Xve au XVIIIe siècle. Lanoo, Tielt. 


\section{Concha Herrero Carretero}

Delmarcel, G. (1999c): Los Honores. Tapisseries flamandes pour Charles Quint. SnoeckDucaju \& Zoon.

Ferrandis, J. (1943): Datos documentales para la Historia del Arte Español. III. Inventarios reales (Juan II a Juana la Loca). Madrid. CSIC.

GarcíA, A: (1999): "Nuevas aproximaciones a la serie El Triunfo de la Eucaristía». El Arte en la Corte de los Archiduques Alberto de Austria e Isabel Clara Eugenia (1598-1633). Un reino imaginado. Madrid, 108-117.

Herrero, C. (1986): “Tapices donados para el culto de la Iglesia vieja». Iglesia y Monarquía. La Liturgia. IV Centenario del Monasterio de El Escorial, Madrid, 93-116.

Herrero, C. (1993): «Cortinas de la colgadura del Dormitorio de Carlos III». Francisco Sabatini 1721-1797. Madrid, 287.

Herrero, C. (1994): «Las tapicerías ricas del Alcázar de Madrid. El Real Alcázar de Madrid». Dos siglos de arquitectura y coleccionismo en la Corte de los Reyes de España. Madrid, 288-307.

Herrero, C. (1996a): "La Real Fábrica de Tapices de Madrid y las innovaciones en tiempos de Francisco de Goya. Realidad y sueño en los viajes de Goya». Actas de las I jornadas de arte en Fuendetodos. Zaragoza, 69-85.

Herrero, C. (1996b): “Tapices y cartones de Goya». Goya 25 Aniversario, Madrid.

Herrero, C. (1998): «Sorpresa de Calais. 1598-1648 Esplendor de España». De Cervantes a Velázquez. Zwollw, 83.

Herrero, C. (1999a): «Tapisseries royales espagnoles de la maison des Habsbourg et acquisitions flammandes de la maison des Bourbons. La tapisserie du XVIIe siècle et les collections européennes». Actes du colloque international de Chambord, 18 et 19 octobre 1996. París, 103-112.

HerRero, C. (1999b): "Fetonte chiede a Febo il permesso di condurre il suo carro". Villa Medici. Il sogno di un cardinale. Collezioni e artisti di Ferdinando de Medici. Academia di Francia a Roma, 238-239.

Herrero, C. (1999c): III. "Tapicería». Summa Artis. Historia General del Arte. Artes Decorativas II. Madrid 45, 131-201.

Herrero, C. (2000): «Les tapisseries de dévotion et la formation de la collection royale espagnole». Âge d'or bruxellois. Tapisseries de la Couronne d'Espagne. Bruselas, 83-88.

Herrero, C. (2000): Catálogo de Tapices del Patrimonio Nacional III. Siglo XVIII. Reinado de Felipe V. Madrid.

Herrero, C. (2001): "Triunfo de José. Tapicería de la Pieza de Cenar de Carlos III». The Majesty of Spain. Jackson, Mississippi.

Junquera, P. y Herrero, C. (1986): Catálogo de Tapices del Patrimonio Nacional. Volumen I: Siglo XVI. Madrid.

Junquera, P. y Día, C. (1986): Catálogo de Tapices del Patrimonio Nacional. Volumen II: Siglo XVII. Madrid.

Sánchez Cantón, F. J. (1950): Libros, Tapices y Cuadros que coleccionó Isabel la Cútólica. Madrid, CSIC.

StEPPE, J.K. (1976): «Inscriptions décoratives contenant des signatures et des mentiuons du lieu d'origine sur des tapisseries bruxelloises de la fin du Xve et du début du XVIIe siècle». Tapisseries bruxelloises de la pré-Renaissance. Bruselas, 193-230.

T'ormo, E. y Sánchez Cantón, F. J. (1919): Los tapices de la Casa del Rey N. S. Notas para el ‘uílogo y para la historia de la colección y de la fábrica. Madrid. 
La Colección de Tapices de la Corona de España...

Valencia de Don Juan, Conde Viudo de (1903): Tapices de la Corona de España. Madrid, 2 t.

VIENA (2000): Der Kriegszug Kaiser Karls V. gegen Tunis. Kartons uns Tapisseries. Kunsthistorisches Museum Wien. 


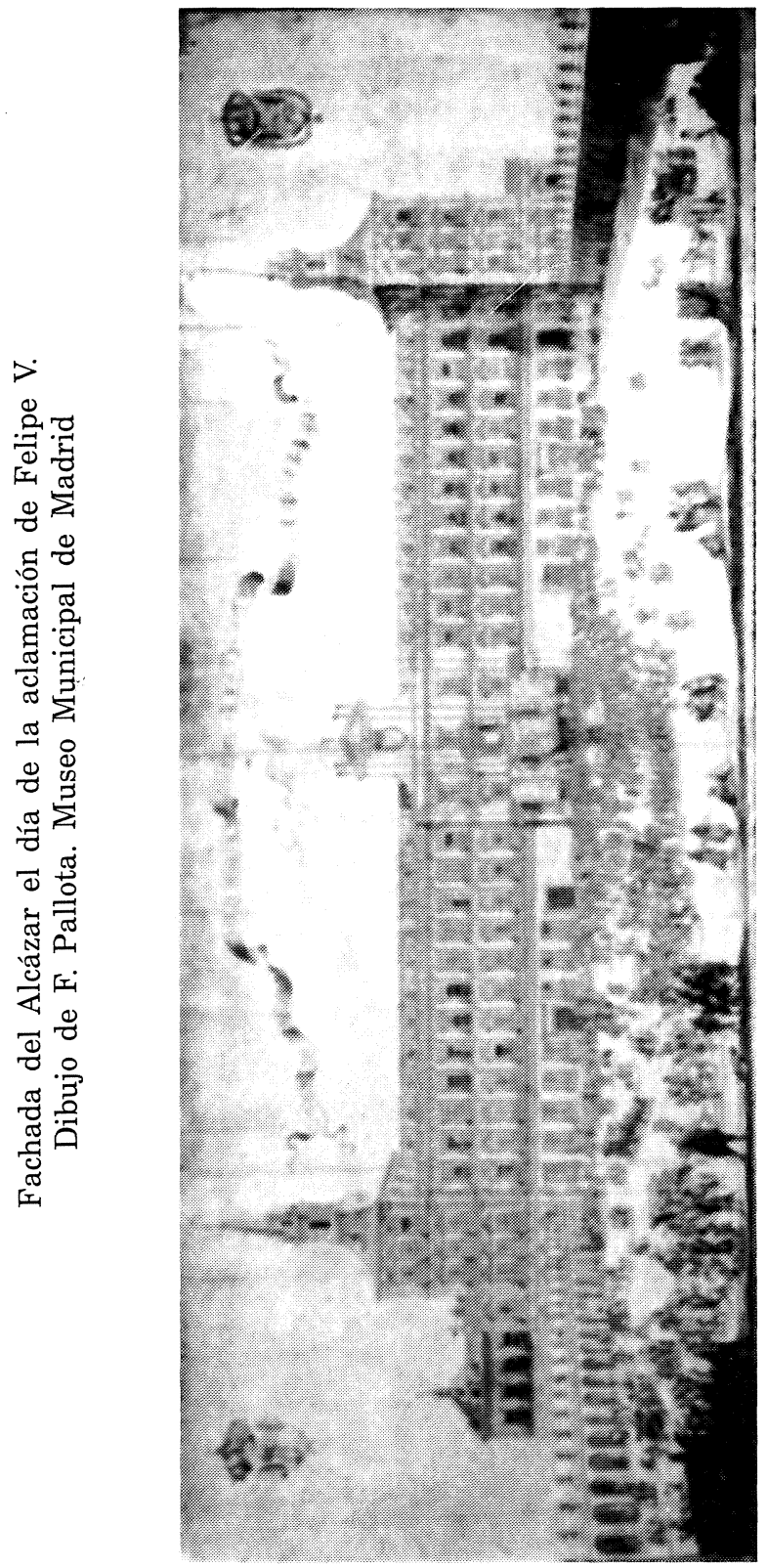


La Colección de Tapices de la Corona de España...

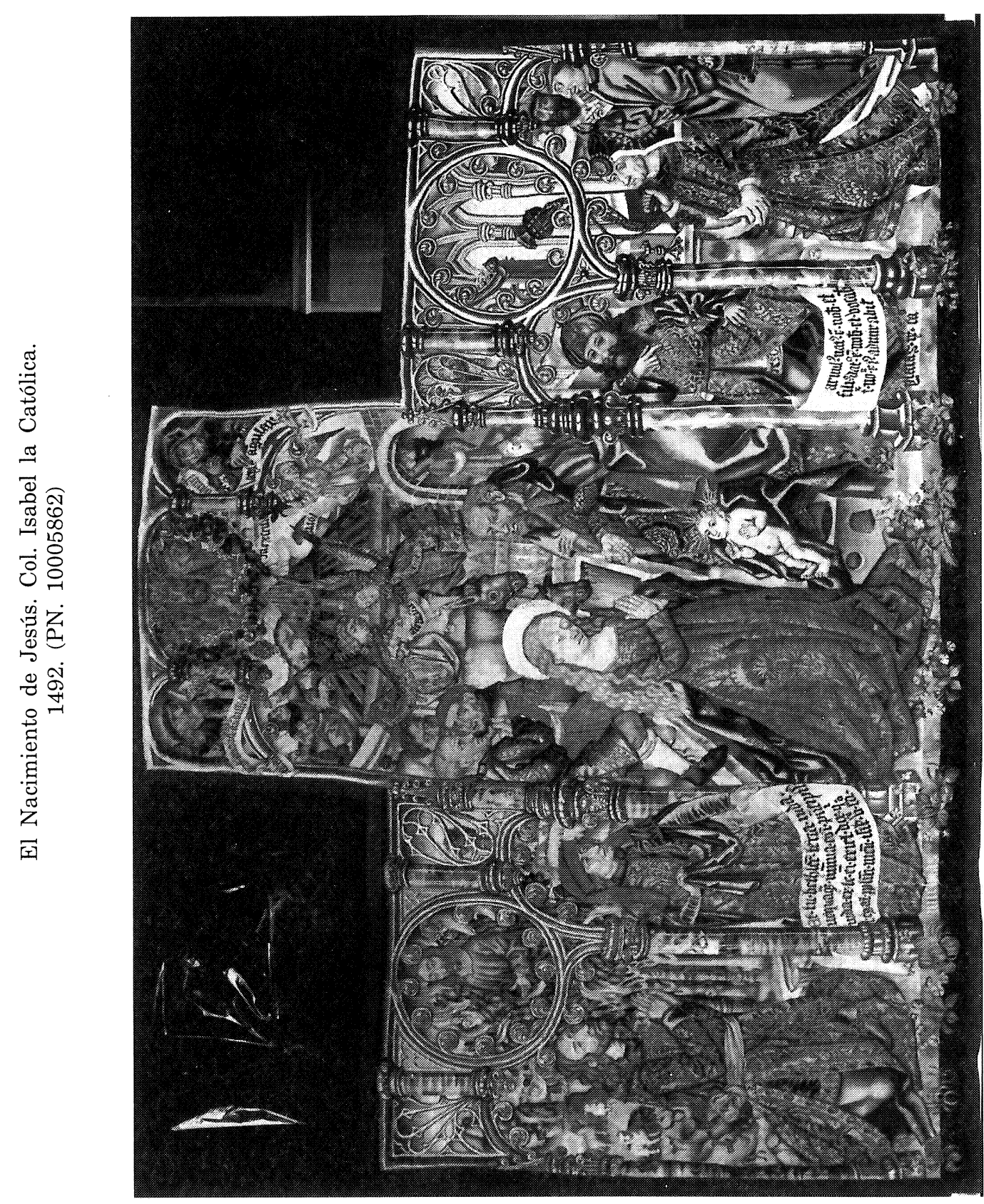




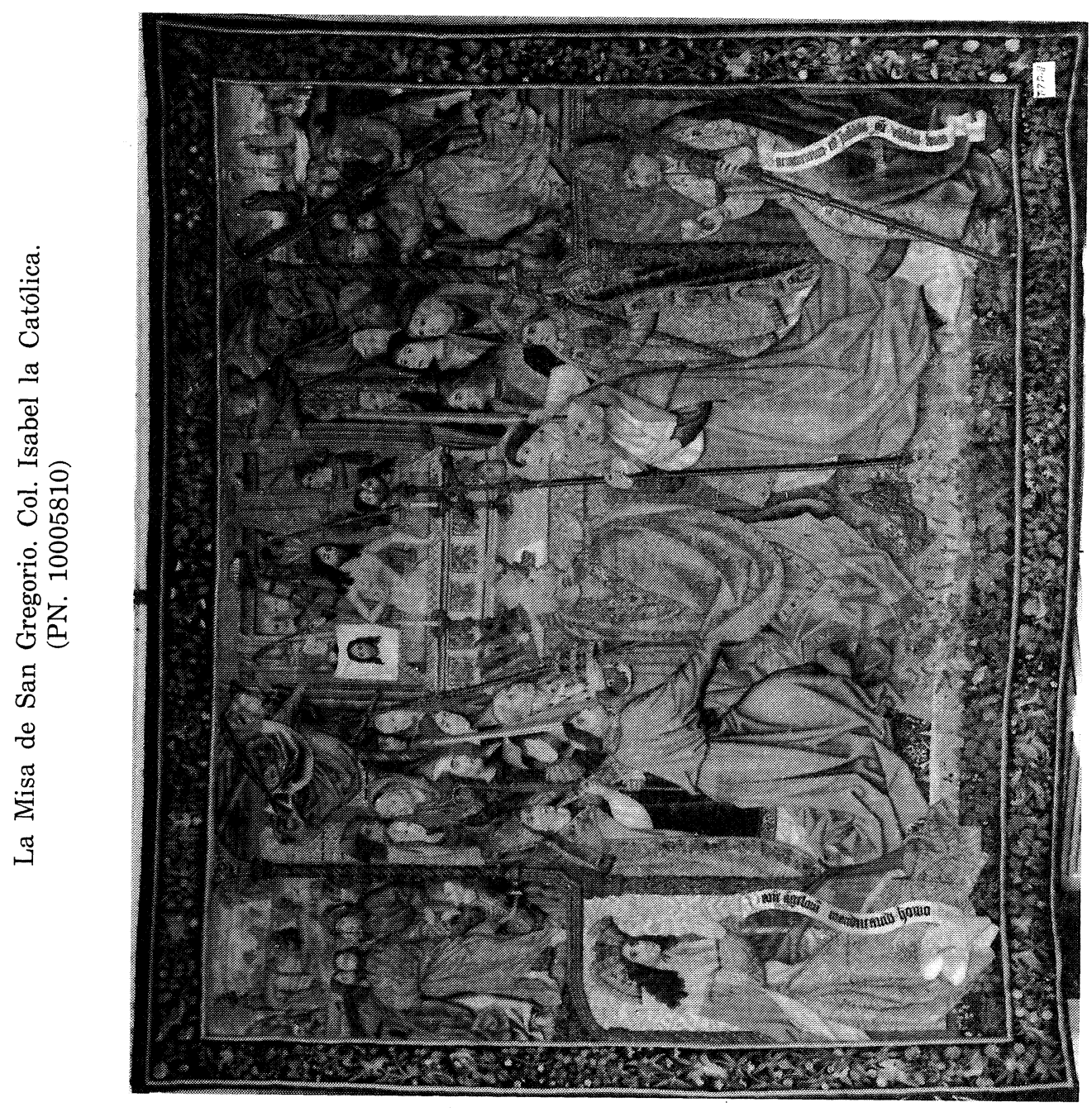




\section{La Colección de Tapices de la Corona de España...}

Juego del ajedrez. Col. Isabel la Católica.

Stiftung Abegg (Riggisberg). Inv. 95

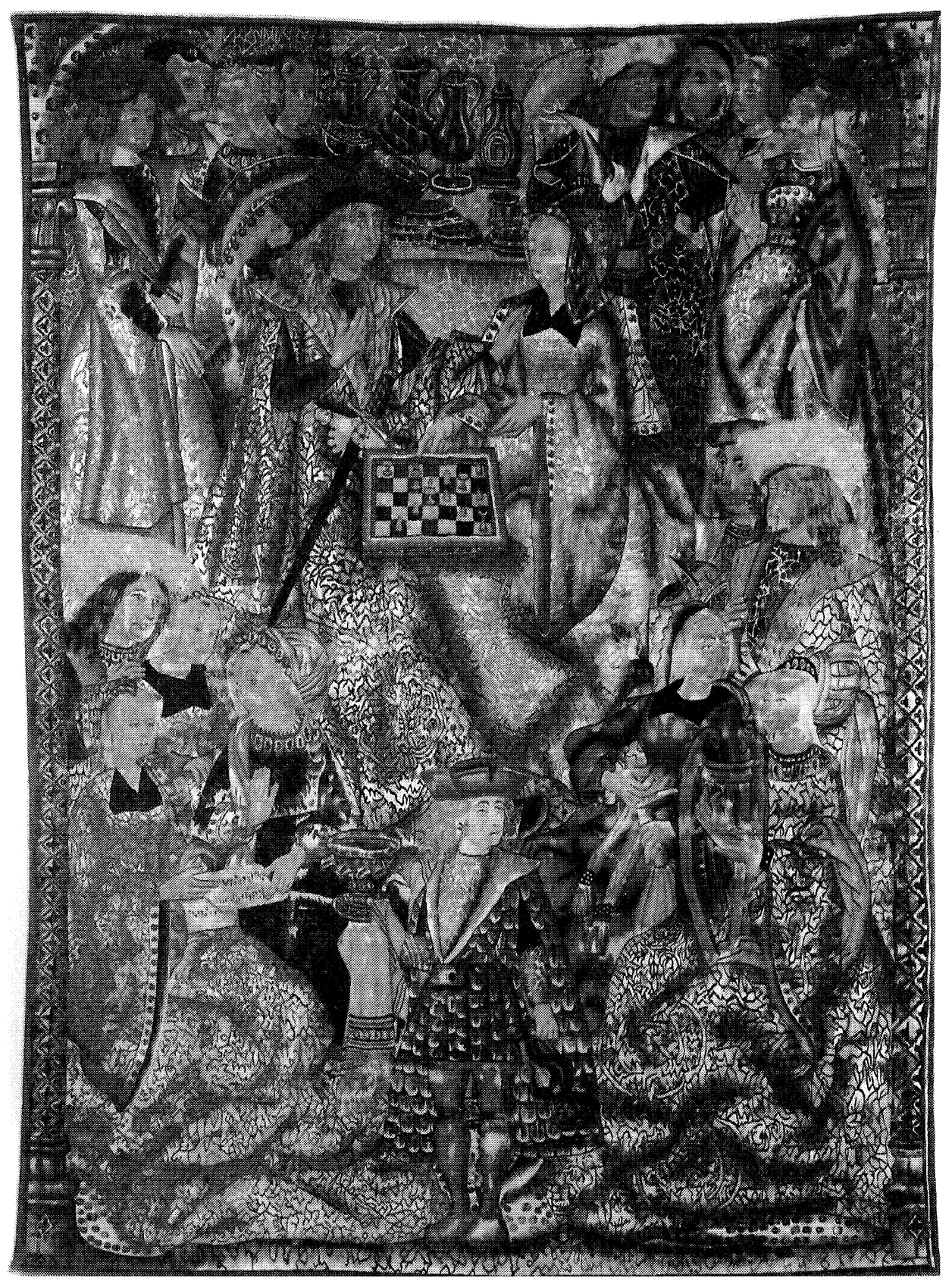




\section{Concha Herrero Carretero}

184

La oración en el huerto. Herencia de Carlos V. (PN 10005833)

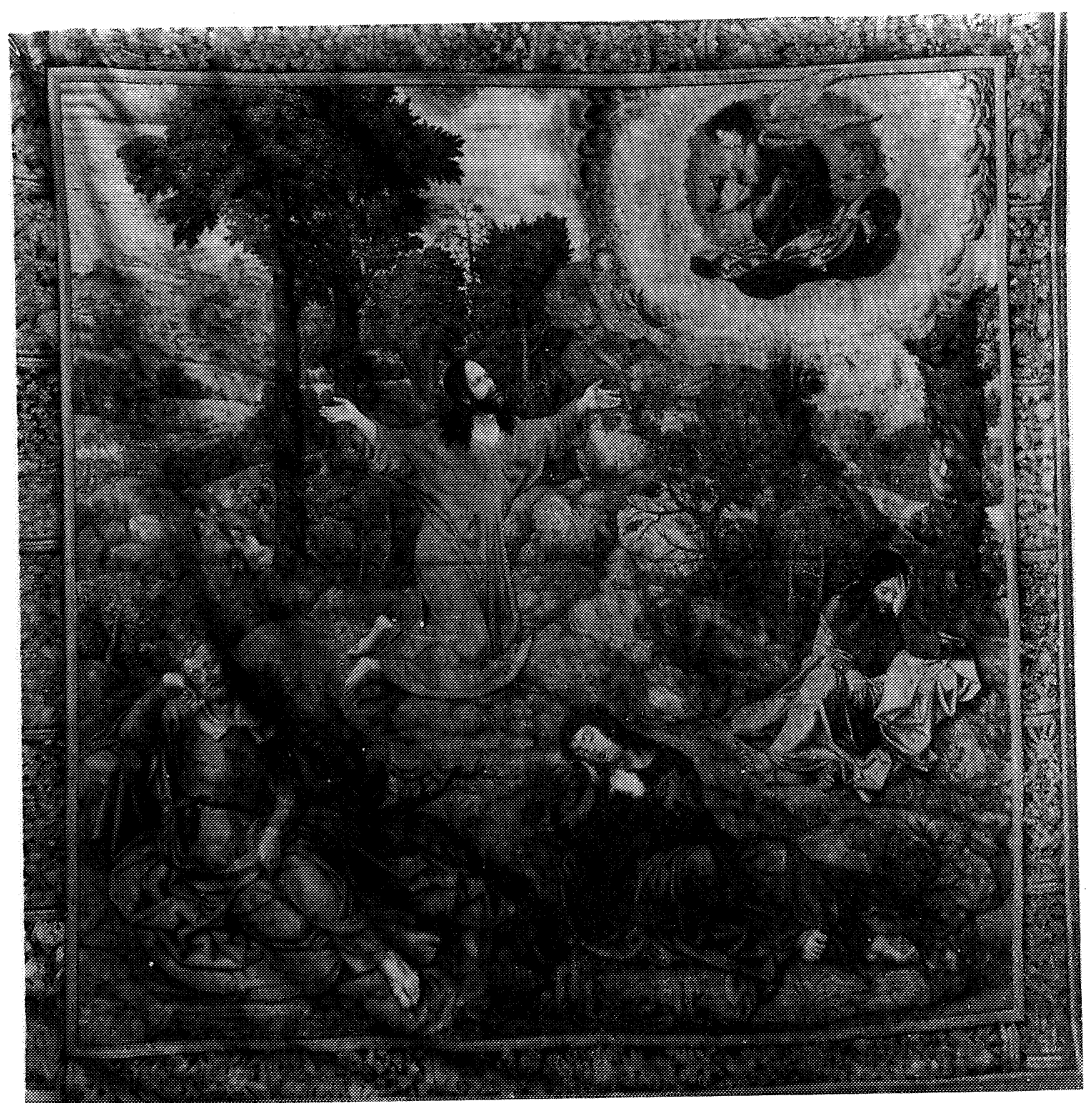


La Colección de Tapices de la Corona de España...

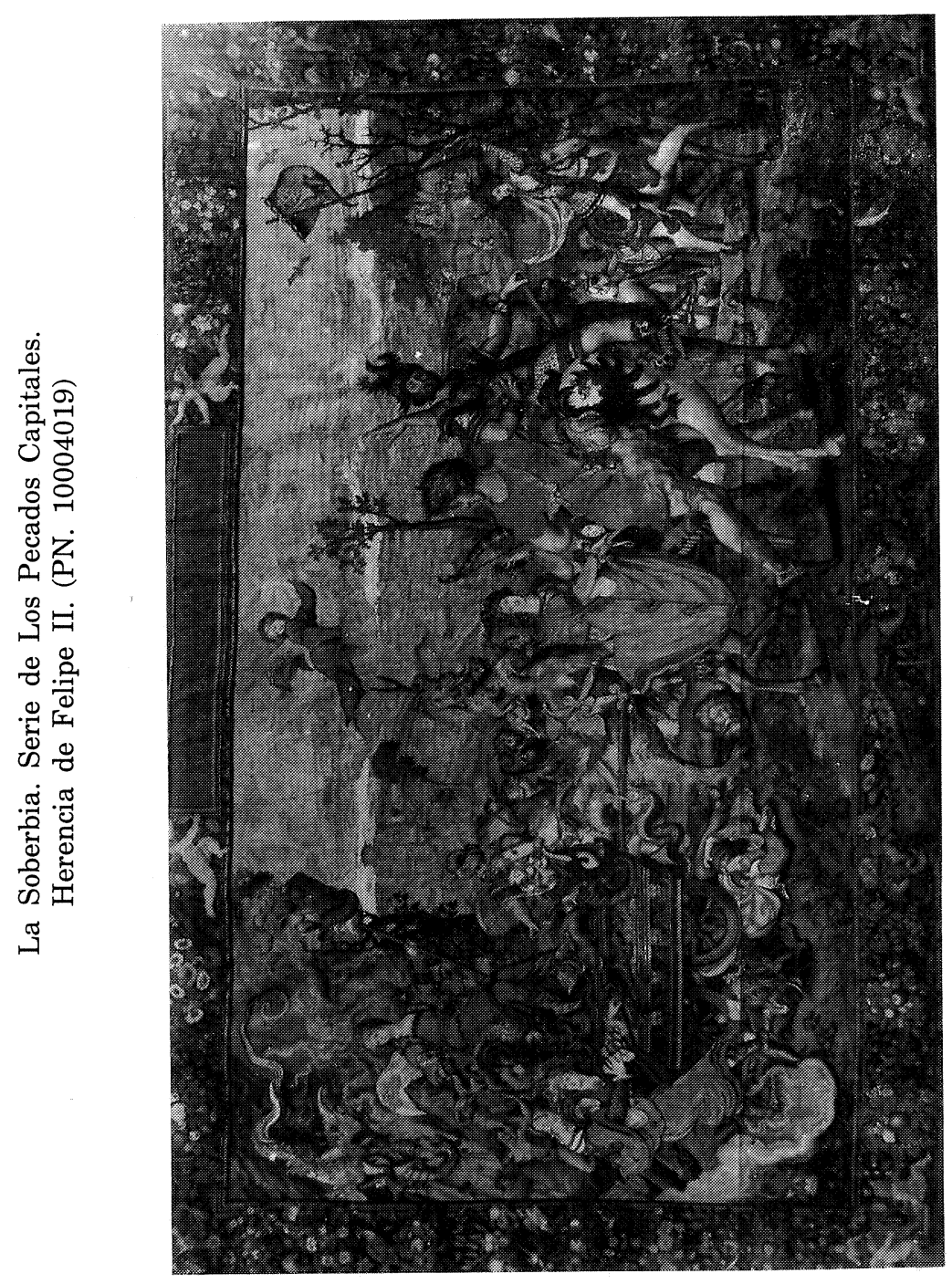




\section{Concha Herrero Carretero}

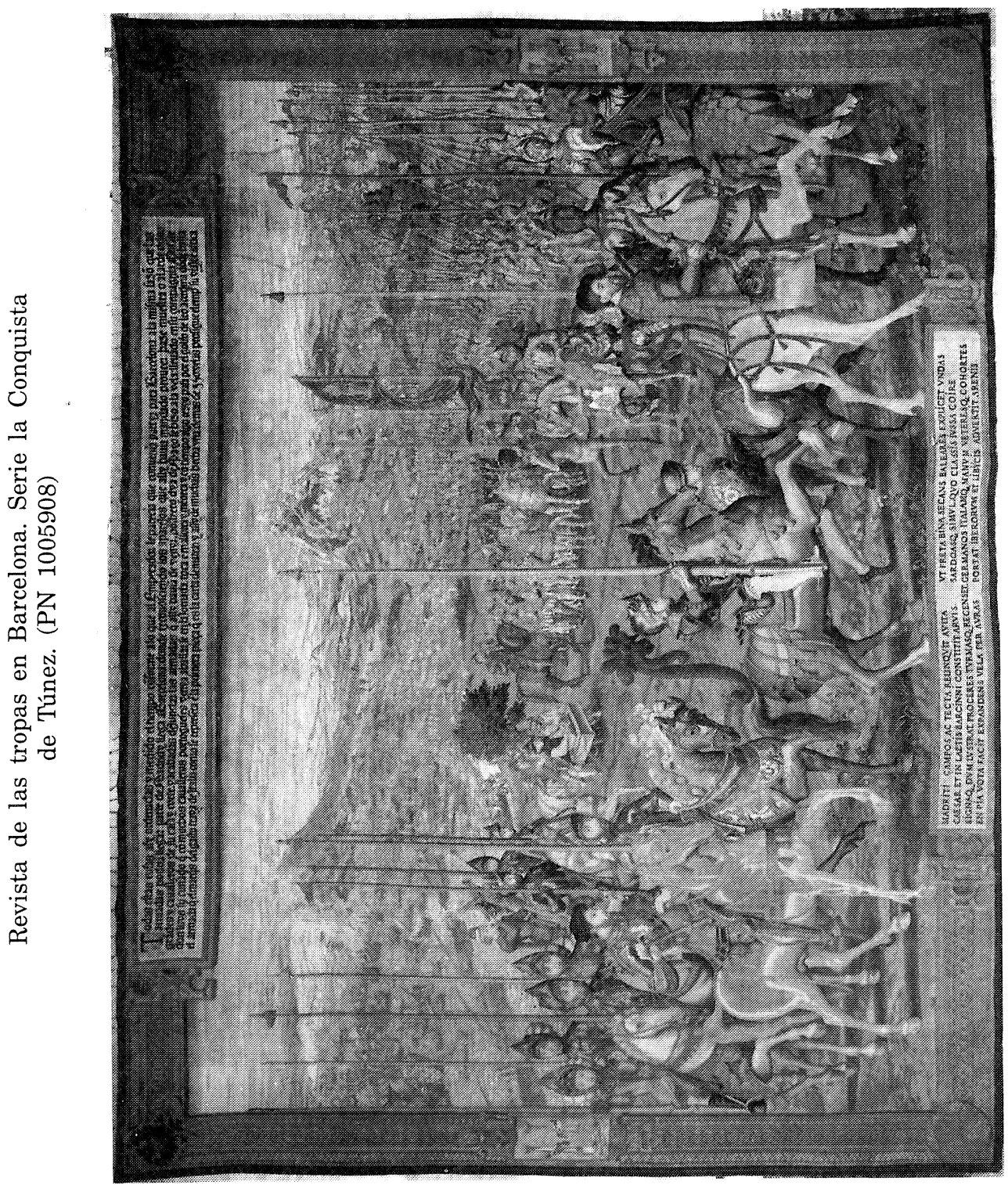


La Colección de Tapices de la Corona de España...

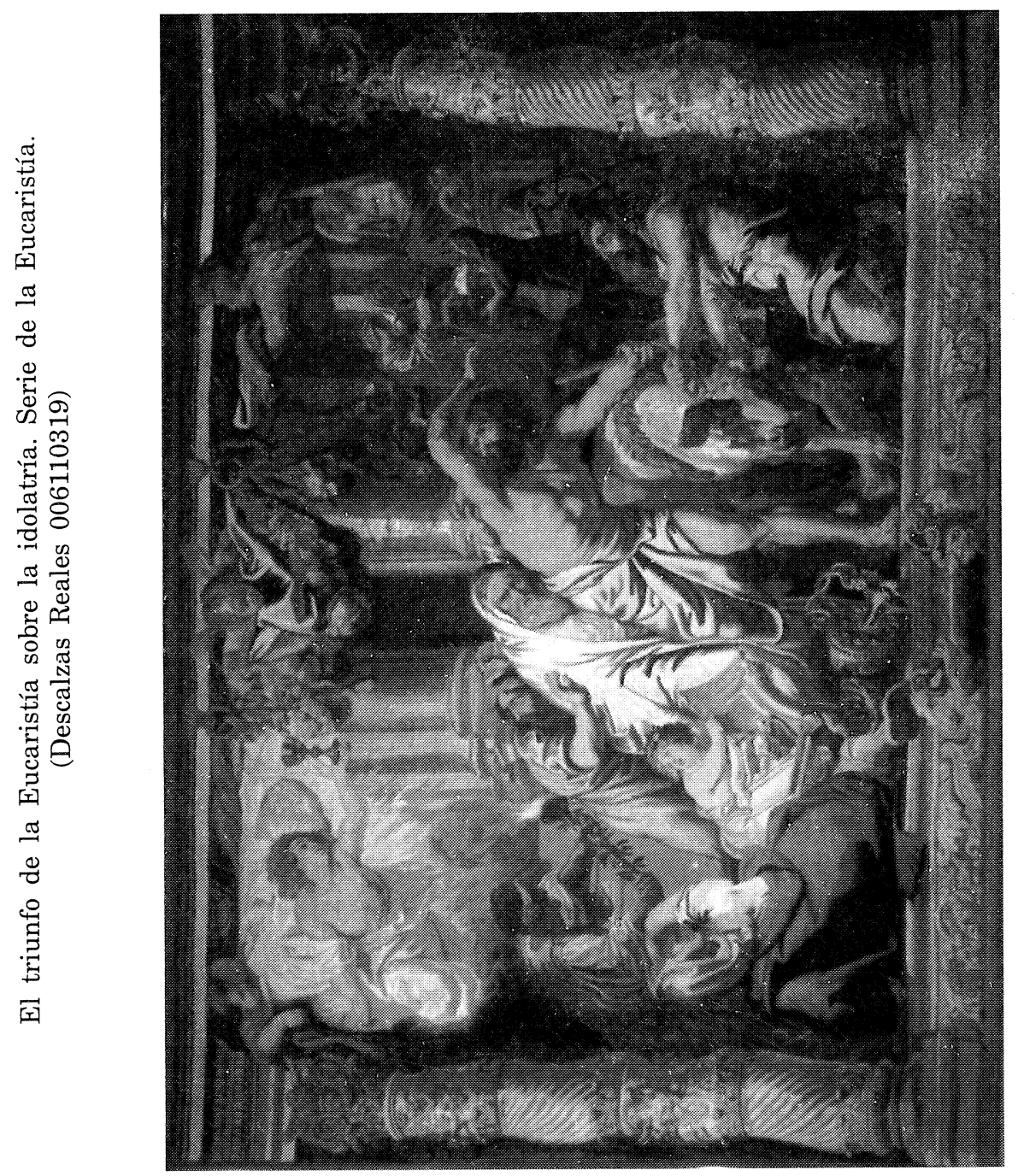




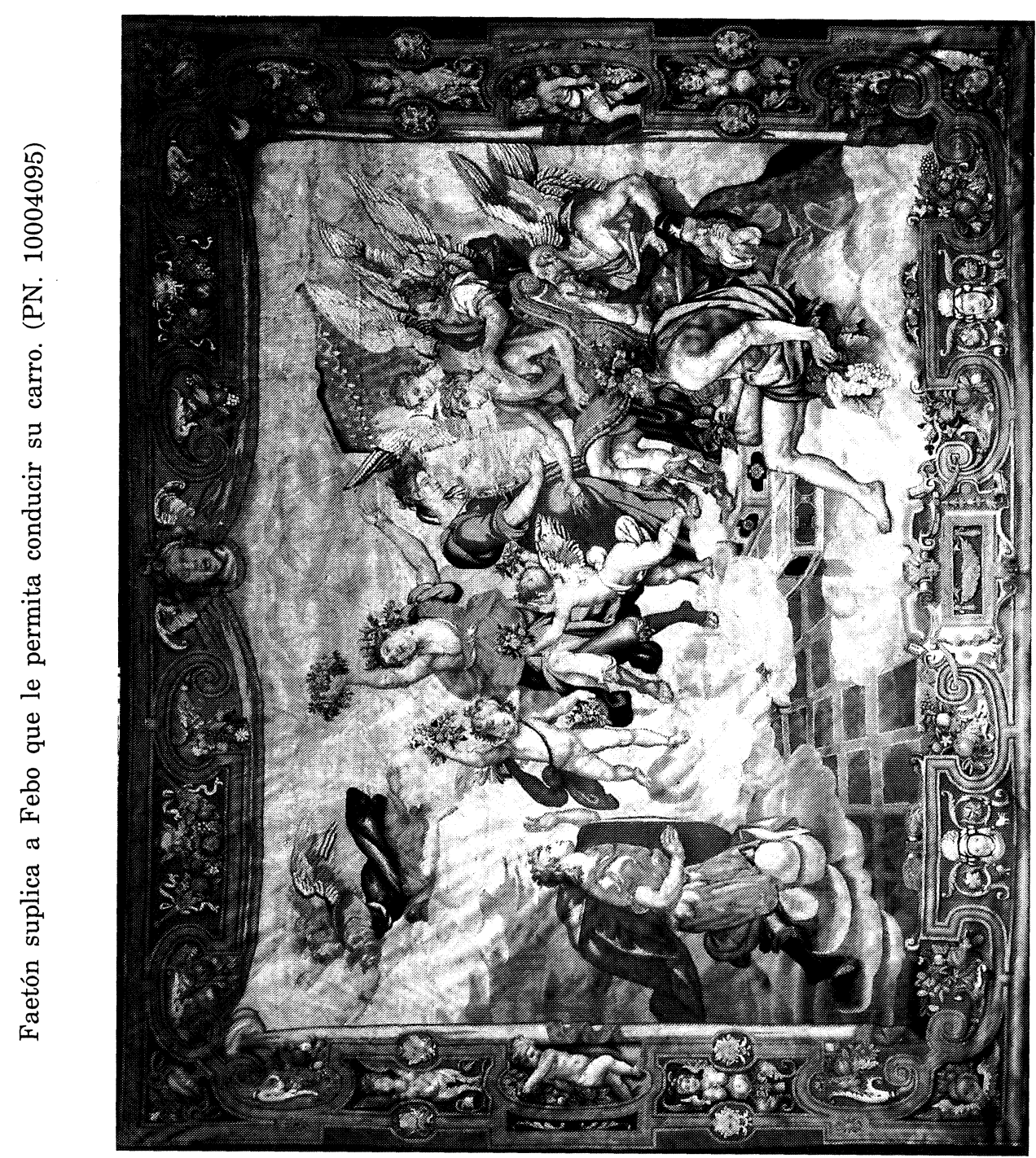


de Decio Serie de la Historia del cónsul Decio. (PN. 10076094)

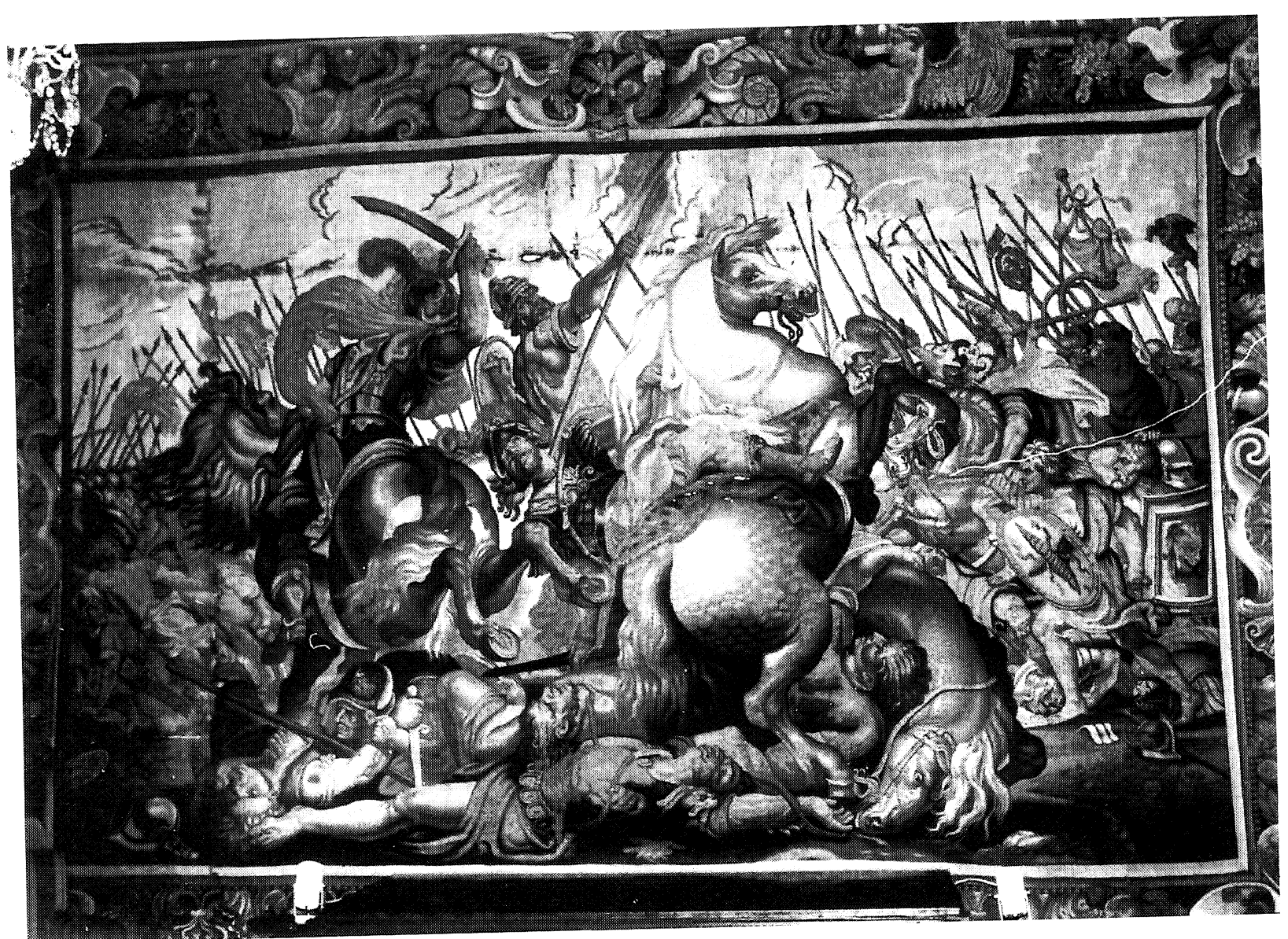




\section{Concha Herrero Carretero}

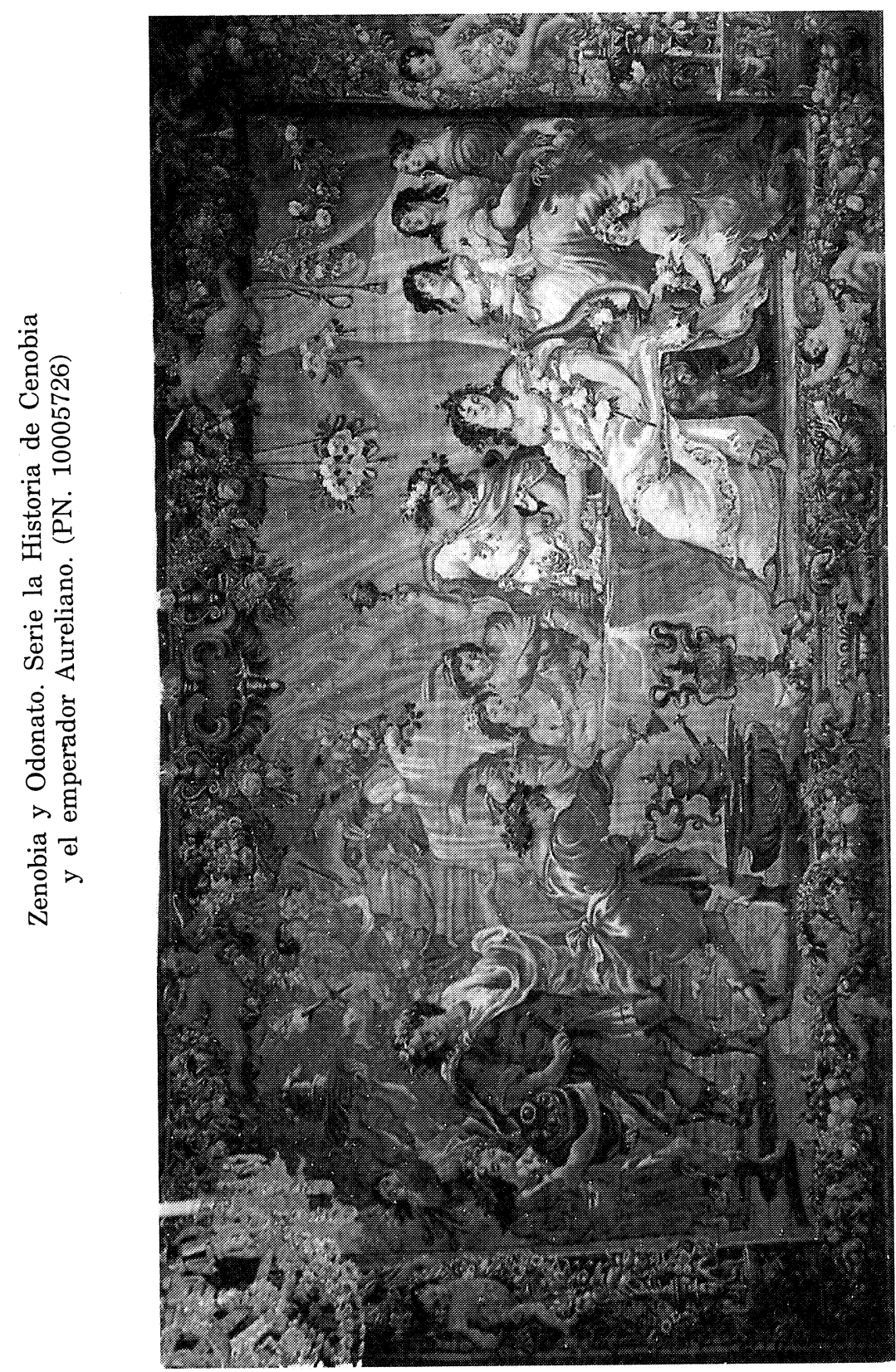


La Colección de Tapices de la Corona de España...

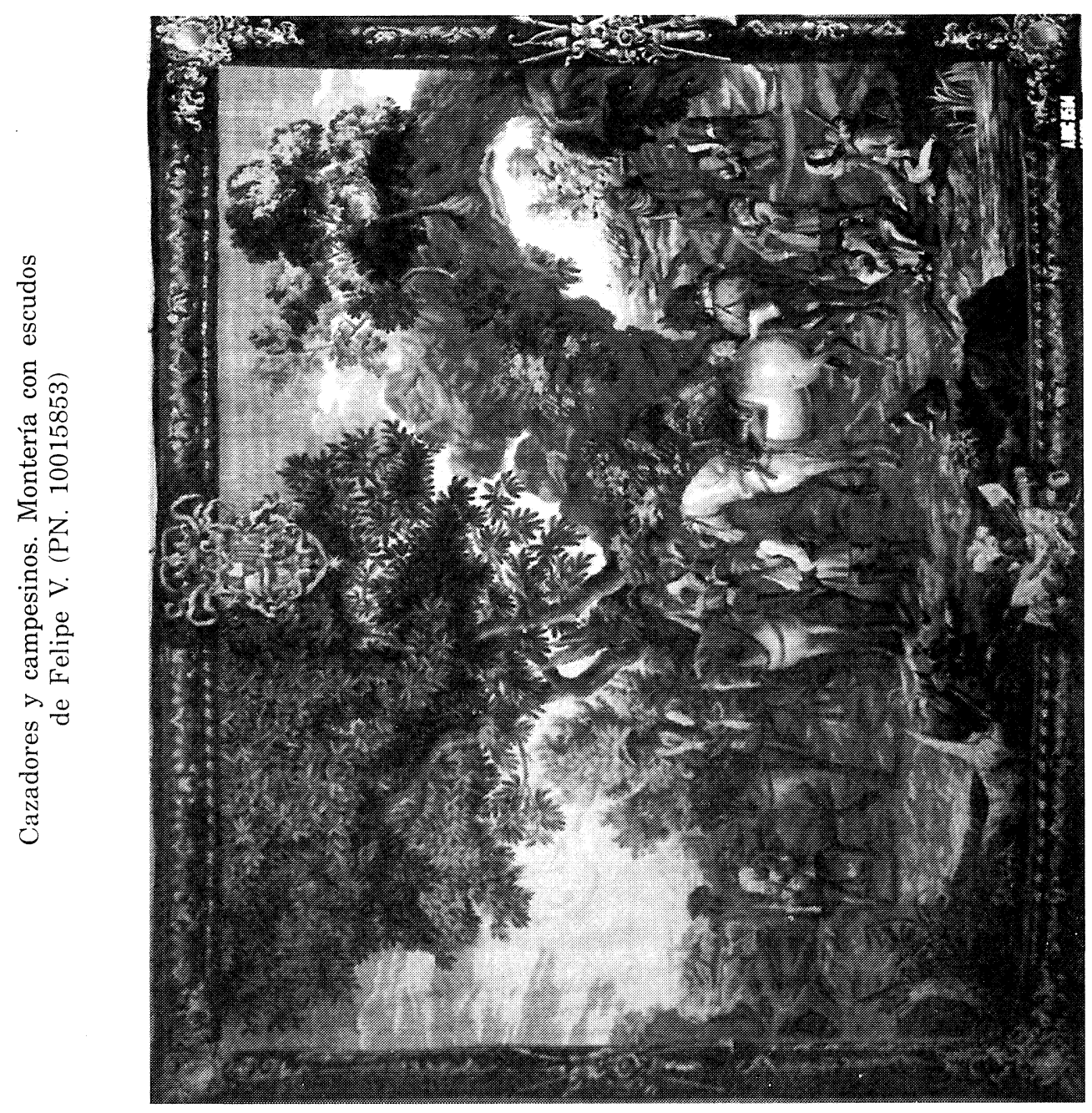




\section{Concha Herrero Carretero}

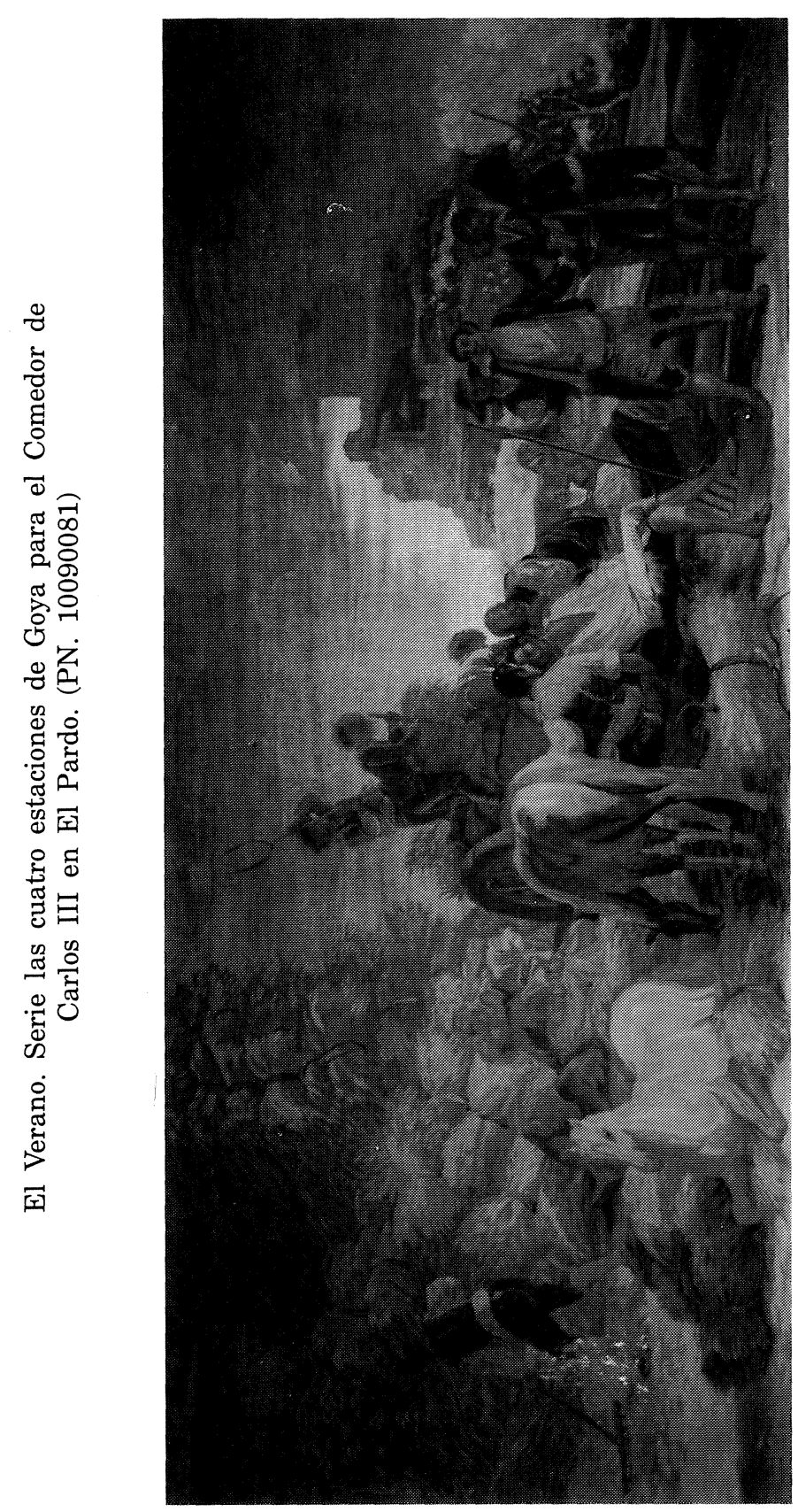

